\title{
УДАЛЕНИЕ ПЕСТИЦИДОВ В ИСКУССТВЕННЫХ ВОДНО-БОЛОТНЫХ УГОДЬЯХ С ГРАВИЙНЫМ ОСНОВАНИЕ
}

\section{PESTICIDES REMOVAL IN WETLANDS WITH A GRAVEL BASE}

A. Butkovskiy

N. Sherman

Summary. Pesticides are widely used in agriculture and forestry. As a result, from circulation, they are present in all components of the natural environment and can negatively affect them. In this paper, a biotechnological method of purifying natural surface water from pesticides is considered, some results of studies of the cleansing ability of an artificially created wetland are presented. The experimental part was carried out at the Center for Environmental Research. Helmholtz in the framework of the DBU program.

Keywords: pesticides, water, treatment, wetlands, treatment facility.

\author{
Бутковский Андрей \\ Н.с., Центр экологических исследований \\ им. Гельмгольца, Лейпциг, Германия \\ Шерман Никита Алексеевич \\ Аспирант, ФГБОУ ВО «Калининградский \\ государственный технический университет», \\ Калининград \\ nik172008@mail.ru
}

Аннотация. Пестициды широко используют в сельском и лесном хозяйствах. В результате из циркуляции они присутствуют во всех компонентах природной среды, могут негативно на них влиять. В данной работе рассматривается биотехнологический метод очистки поверхностной природной воды от пестицидов, представлены некоторые результаты исследований очищающей способности искусственно созданного водно-болотного угодья. Экспериментальная часть проводилась в Центре экологических исследований им. Гельмгольца в рамках программы DBU.

Ключевые слова: пестициды, вода, очистка, водно-болотные угодья, очистное сооружение.

ности, почвы и микроорганизмов для очистки сточных вод. В зависимости от типа сточных вод, дизайн водно-болотного угодья должен быть соответствующим образом адаптирован. Водно-болотные угодья используются для очистки как бытовых, так и промышленных сточных вод.

Эти установки имеют определенные преимущества по сравнению с механической и химической обработкой, а также аэрированными биореакторами (или так называемым процессом с активным илом), а именно полное отсутствие химических реагентов, низкое или нулевое потребление энергии, отсутствие потребления невозобновляемой энергии, относительно низкие затраты на строительство и эксплуатацию, улучшенная рекреационная привлекательность района использования.

В сельском хозяйстве Калининградской области интенсивно применяются удобрения и пестициды, что приводит к поступлению в биосферу различных химических веществ, которые могут негативно влиять на окружающую среду (рис. 1). Пестициды могут быть опасными даже при низких концентрациях, так как считается, что эти соединения убивают растения (гербициды), беспозвоночных (инсектициды) или грибки (фунгициды). 
Таблица 1. Перечень пестицидов, используемых в опыте

\begin{tabular}{|c|c|}
\hline Пестицид & Тип \\
\hline MCPA & $\Gamma$ \\
\hline Бентазон (Bentazone) & $\Gamma$ \\
\hline Металаксил (Metalaxyl) & $\Phi$ \\
\hline Пропиконазол (Propiconazole) & $\Phi$ \\
\hline Имидаклоприд (Imidacloprid) & n \\
\hline \multicolumn{2}{|c|}{$\begin{array}{l}\text { МСРА (2-метил-4-хлорфеноксиуксусная кислота) является эффективным, широко используемым гербицидом [3-4]; } \\
\text { Бентазон - контактный гербицид для борьбы с сорными растениями после всходов сорняков [5]; } \\
\text { Металаксил - системный фунгицид защитного и искореняющего действия для борьбы с болезнями [6]; } \\
\text { Пропиконазол - используется методом опрыскивания в качестве системного фунгицида с широким спектром действия } \\
\text { на посевах зерновых [7]; } \\
\text { Имидаклоприд - системный инсектицид для борьбы с сосущими насекомыми, включая резистентные виды, с почвенными } \\
\text { вредителями [8]. }\end{array}$} \\
\hline
\end{tabular}

\section{обработка пестицидами}
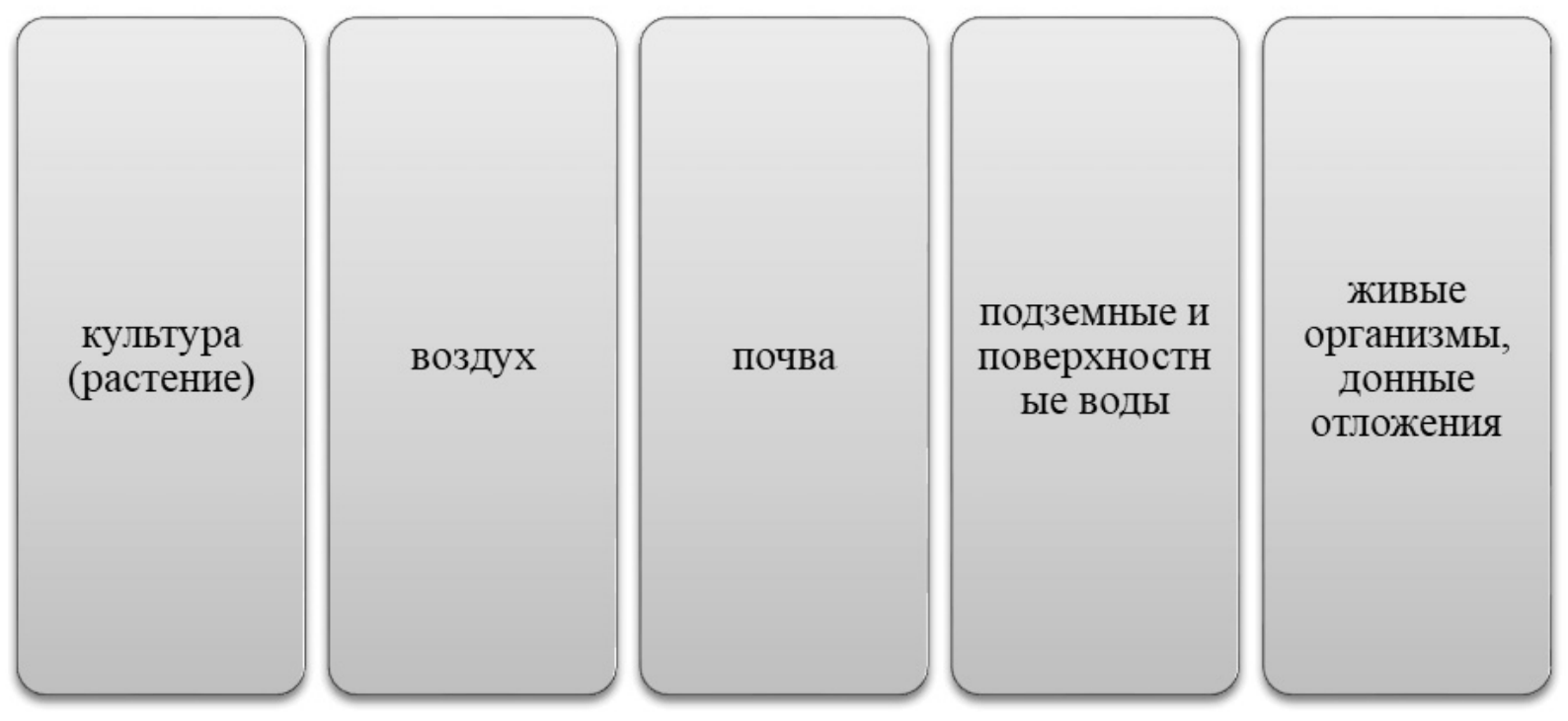

Рис. 1. Циркуляция пестицидов во внешней среде

В большинстве случаев пестициды попадают в воду при неправильной технологии опрыскивания растений, в результате вымывания из почвы, с талыми и дождевыми водами при смыве с почвенного покрова и растений.

Существует ряд методов и технологий в области природоохранных мероприятий, позволяющих удалять или снижать уровень пестицидов в воде. Авторы статьи считают, что наиболее перспективным является биотехнологический подход - применение для очистки вод искусственно созданных водно-болотных угодий - это технические системы, которые используют природные функции растительности, почвы и организмов [2].

В 2018-2019 гг. в Центре экологических исследований им. Гельмгольца были проведены эксперименты по определению очищающей способности водно-болотной растительности от пестицидов.

Для определения степени очистки, загрязнённой пестицидами воды (табл. 1), была создана экспериментальная установка (рис. 2), состоящая из двух параллельных горизонтальных водно-болотных угодий под- 


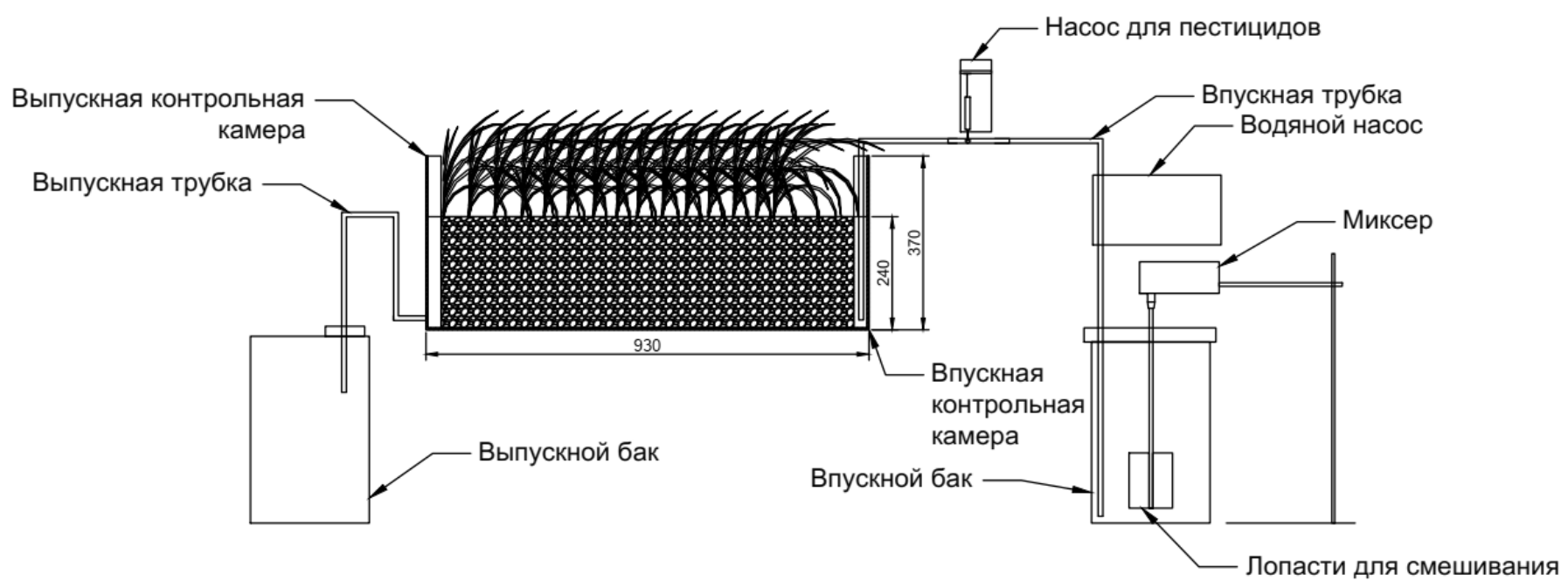

Рис. 2. Схема экспериментальной установки

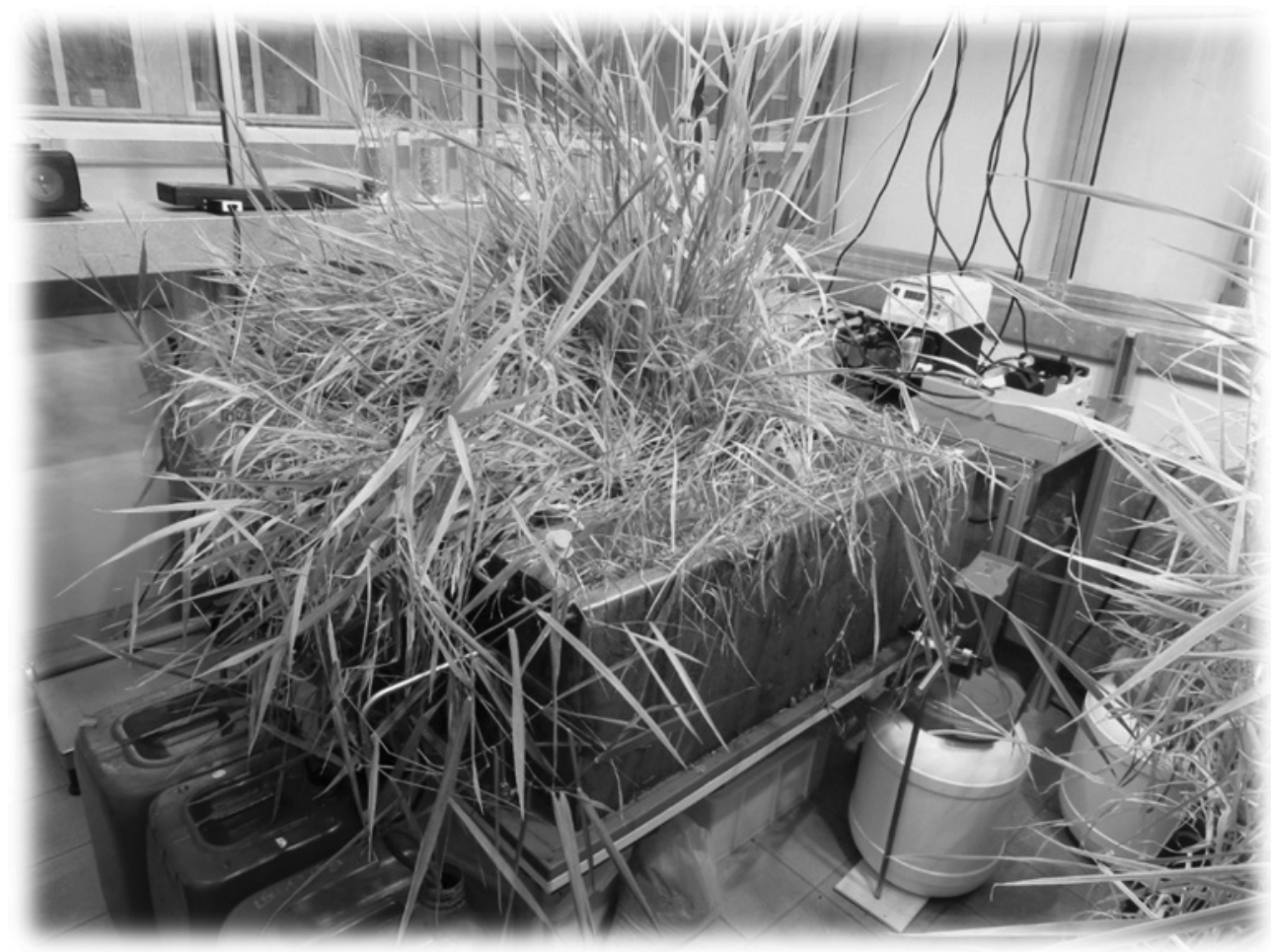

Рис. 3. Экспериментальная установка

поверхностного потока, которые используют твердые грунты, засаженные водно-болотной растительностью.

\section{1. Материалы и метолы}

\section{1. Исследовательская установка}

Экспериментальная установка состоит из 2 параллельных горизонтальных водно-болотных угодий, в которых создается неподвижное ложе с растительностью водно-болотных угодий. Наиболее важные параметры конструкции перечислены в таблице 2. Вода вытекает из впускного бака с помощью водяного насоса. Контрольные камеры устанавливаются в начале и в конце сооружений. В этих камерах можно измерять различные параметры и отбирать пробы для измерений загрязняющих веществ. Уровень твердой среды на заболоченном участке составляет 24 см. Вода удерживается под поверхностью и течет горизонтально от входа до выхода. После прохождения через заболоченную 
Таблица 2. Гидравлический баланс

\begin{tabular}{|l|l|l|}
\hline \multirow{2}{*}{ Обозначение установки } & Потери воды, л / м2 * сут & $\mathbf{2 9 . 0 1 . 2 0 1 9}$ \\
\cline { 2 - 3 } & $\mathbf{0 5 . 1 0 . 2 0 1 8}$ & 2,56 \\
\hline C & - & 10,75 \\
\hline
\end{tabular}

Таблица 3. Значения номинального гидравлического времени удержания

\begin{tabular}{|l|l|}
\hline Обозначение установки & Среднее HRT, дни \\
\hline C & 7,6 \\
\hline F & 12,8 \\
\hline
\end{tabular}

территорию очищенная вода собирается в выходном бассейне. Установка была расположена в лаборатории водно-болотных угодий в Центре экологических исследований им. Гельмгольца - UFZ в условиях контролируемой температуры и освещения.

Установка имеет следующие параметры:

- Объем (полный/рабочий) - 50/33,5 л;

- Площадь водно-болотного угодья - 0,1395 м²;

- Объем первичного и конечного бака - 20 л;

- Расход - 2,39 л/сут.

Принции работь установки. Вода поступает из бака в «водно-болотное угодье» с помощью водяного насоса, уровень грунтов внутри «водно-болотного угодья» составляет 0,24 м. После прохождения заболоченного участка, вода собирается в выпускном баке. В впускном и выпускном баках имеются контрольные камеры, в которых можно наблюдать за состоянием воды и отбирать пробы.

Эксперименты проводились в двух лотках с загрузкой гравием. Предварительно определялись их фильтрационные свойства:

В данном исследовании в качестве фиторемидианта использовался канареечник тростниковидный Phalaris arundinacea. Данное растение стабильно произрастает в широком диапазоне климатических условий и обладает высокой способностью удалять загрязняющие вещества в своей ризосфере.

Пестициды добавляли в лоток с 27 января по 24 февраля 2019 года с использованием перфузионного насоса 0,5 мг / л. Эта концентрация была выбрана из-за ограниченности анализаторов. Тем не менее, такие высокие концентрации могут также возникнуть в сельскохозяйственном стоке, если пестициды используются чрезмерно.

\section{2. Аналитические измерения}

Пестициды анализировали методом жидкостной хроматографии, масс-спектрометрии (ЖХ-МС) в Норвежском институте биоэкономических исследований. Образцы для анализа пестицидов фильтровали через фильтр 0,45 мкм и хранили в $20 \%$ метаноле при $-20{ }^{\circ} \mathrm{C}$ до анализа.

\section{3. Расчеты}

Номинальное гидравлическое время удержания (HRT) определяется как отношение полезного объема водно-болотных угодий к средней скорости потока.

$$
t=\left(V_{w}\right) * \epsilon / Q_{a v e}
$$

Где $Q_{\text {ave }}$ - средняя скорость потока, $V_{w}$ - объем водно-болотных угодий, $\varepsilon$ - пористость водно-болотных угодий.

$$
Q_{\text {ave }}=\frac{Q_{0}+Q_{\theta}}{2}
$$

Где $Q_{o}-$ Подводящая скорость, $Q_{e}-$ Отводящая скорость.

Коэффициент суммарного испарения рассчитывали, как отношение объема сточных вод к объему подаваемой воды.

\section{3. Результаты}

\section{1. Ввод реактора в эксплуатацию}

С сентября по декабрь был обеспечен рост растений для создания стационарных условий.

В этой таблице показаны потери воды 5 октября 2018 года и 29 января 2019 года. Для установки С от- 
Таблица 8. Данные о состоянии установок с 1 по 4 недели

\begin{tabular}{|c|c|c|c|c|c|}
\hline \multirow{2}{*}{$\begin{array}{l}\text { Обозначение } \\
\text { установки }\end{array}$} & \multicolumn{5}{|c|}{ Пестицид } \\
\hline & MCPA & Бентазон & Металаксил & Пропиконазол & Имидаклоприд \\
\hline C & - & - & - & - & - \\
\hline $\mathrm{F}$ & - & - & - & - & - \\
\hline \multicolumn{6}{|c|}{ Удаление за 2 неделю (\% от средней концентрации притока) } \\
\hline \multirow{2}{*}{$\begin{array}{l}\text { Обозначение } \\
\text { установки }\end{array}$} & \multicolumn{5}{|c|}{ Пестицид } \\
\hline & MCPA & & MCPA & & MCPA \\
\hline C & -22 & C & -22 & C & -22 \\
\hline $\mathrm{F}$ & 1 & $\mathrm{~F}$ & 1 & $\mathrm{~F}$ & 1 \\
\hline Удаление за 3 & (\% от c & й концентр & рритока) & & \\
\hline \multirow{2}{*}{$\begin{array}{l}\text { Обозначение } \\
\text { установки }\end{array}$} & \multicolumn{5}{|c|}{ Пестицид } \\
\hline & MCPA & Бентазон & Металаксил & Пропиконазол & Имидаклоприд \\
\hline C & 12 & 17 & 21 & 98 & 16 \\
\hline $\mathrm{F}$ & 23 & -22 & 70 & 100 & 43 \\
\hline \multicolumn{6}{|c|}{ Удаление за 4 неделю (\% от средней концентрации притока) } \\
\hline \multirow{2}{*}{$\begin{array}{l}\text { Обозначение } \\
\text { установки }\end{array}$} & \multicolumn{5}{|c|}{ Пестицид } \\
\hline & MCPA & Бентазон & Металаксил & Пропиконазол & Имидаклоприд \\
\hline C & 44 & 43 & 42 & 100 & 40 \\
\hline $\mathrm{F}$ & 42 & 2 & 66 & 100 & 63 \\
\hline
\end{tabular}

сутствуют данные в первой половине октября, поскольку установки была повреждена. Понятно, что с ростом растений суммарное испарение воды увеличивается.

Значения HRT (таблица 3) рассчитываются как средние значения за период с 27.12.2018 по 11.02.2019. Это уравнение обычно используется для определения количества сырья, используемого в данном объеме реактора. HRT является важным параметром в очистке сточных вод, напрямую влияющим на требования к проектированию, эксплуатации / инвестициям и энергии. В целом, более высокие HRT приведут к более высоким инвестиционным затратам и пространственным требованиям, но в то же время предложат более высокую эффективность разделения. Следовательно, другое значение HRT также оказывает значительное влияние на эффективность очистки сточных вод водно-болотных угодий.

\section{2. Удаление пестицидов}

Забор воды производился раз в неделю.

Данные за первую неделю отсутствуют, так как пробы для анализов были отобраны спустя 3 дня после начала добавления пестицидов и в выпускной контрольной камере они отсутствуют.

По вышеприведенным данным можно видеть, что на первой, второй и третьей неделях имеются отрицательные значения удаления пестицидов. Это значит, что кон- центрация пестицидов в выпускной контрольной камере выше, чем во впускной контрольной камере. Это может происходить вследствие того, что система еще не стабилизировалась и не произошло равномерного распределения загрязнителей по очистной установке. По данным удаления пестицидов за 4 неделю можно сделать вывод, что к этому времени система начала стабилизироваться и концентрация всех загрязнителей снизилась.

По данным удаления металаксила из установки $F$ на второй, третьей и четвертой неделях можно сделать вывод, что система достигла своего оптимального уровня удаления данного загрязнителя в диапазоне от 66 до 73\% от общей концентрации.

Данные об удалении пропиконазола в установках C и $\mathrm{F}$ так велики, поскольку наблюдалась низкая концентрация притока пропиконазола, так как сорбция этого гидрофобного соединения уже произошла в резиновой трубке подачи.

\section{Зак^ючение}

Проведенный опыт показал, что «водно-болотные угодья» достаточно просты в установке, обслуживании и эксплуатации. Они не требуют постоянного наблюдения, добавления различных реагентов, подключения к системе электроснабжения. Более того, они справляются с различными видами загрязнителей, включая пестициды. Их недостатком можно назвать то, что в рамках проведенного эксперимента они не обеспе- 
чили степень очистки, соответствующую требованиям нормативных документов в этой области. Так как эксперимент завершился на четвертой неделе, можно предположить, что с течением времени степень очистки различных пестицидов могла увеличиться. Но тем не менее, по данным за четвертую неделю можно сделать вывод, что очистная установка показала положи- тельную степень удаления всех пяти наименований пестицидов. На основании этого можно сделать вывод, что хоть система не обеспечивает достаточную степень очистки, их использование в районах активного ведения сельского хозяйства может значительно снизить количество загрязнителей, попадающих как в прилегающие реки и водоемы, так и в грунтовые воды.

\section{ЛИТЕРАТУРА}

1. Stottmeister U., Wießner A., Kuschk P., Kappelmeyer U., Kästner M., Bederski 0., Müller R.A., 2003. Effects of plants and microorganisms in constructed wetlands for wastewater treatment. Biotechnology Advances 22, 93-117.

2. Wagner S., Fantke P., Theloke J., Friedrich, R., 2010. Quantification of pesticides used in agriculture in the EU-27. Geophysical Research Abstracts Vol. 12, EGU2010-12273, EGU General Assembly.

3. 2M-4X, MCPA. [Электронный ресурс]. URL: http://www.cnshb.ru/akdil/0034/base/2/000126.shtm (Дата обращения 15.07.2019 г.).

4. 4-Chloro-2-methylphenoxy. [Электронный ресурс]. URL: https://pubchem.ncbi.nlm.nih.gov/compound/mсра (Дата обращения 15.07.2019 г.).

5. Бентазон. [Электронный ресурc]. URL: http://www.cnshb.ru/akdil/0034/base/RB/000021.shtm (Дата обращения 15.07.2019 г.).

6. МЕТАЛАКСИЛ (алацид, апрон, ридомил). [Электронный ресурс]. URL: http://www.cnshb.ru/akdil/0034/base/RM/000362.shtm (Дата 0бращения 15.07.2019 г.).

7. ПРОПИКОНАЗОЛ (десмел, низонит, практик, радар, тилт, трифон). [Электронный ресурс]. URL: http://www.cnshb.ru/akdil/0034/base/RP/000393.shtm (Дата обращения 15.07.2019 г.).

8. ИМИДАКЛОПРИД (адмир, гаучо, копфидор, премьер). [Электронный ресурс]. URL: http://www.cnshb.ru/akdil/0034/base/RI/000545.shtm (Дата 0бpaщения 15.07.2019 г.).

9. Phalaris arundinacea L. [Электронный ресурс]. URL: https://www.eddmaps.org/ipane/ipanespecies/grass/phalaris_arundinacea.htm (Дата обращения 15.07.2019 г.).

10. Жуков Б.Д. Экологическое домостроение. Устройства и технологии децентрализованной очистки бытовых сточных вод: Аналит. обзор / СО РАН. ГПНТБ.- Новосибирск, 1999.- 113 с. 